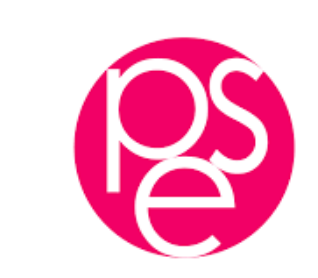

PARISSCHOOL OFECONOMICS
ECOLED'ECONOMIEDEPARIS

WORKING PAPER N $2017-60$

Longterm decision making under the threat of earthquakes

Carmen Camacho

Yu Sun

JEL Codes: C6, 013, 021, 044, Q54

Keywords: Bayesian Learning, Earthquakes, Prevention, Policy Making, Economic

Growth

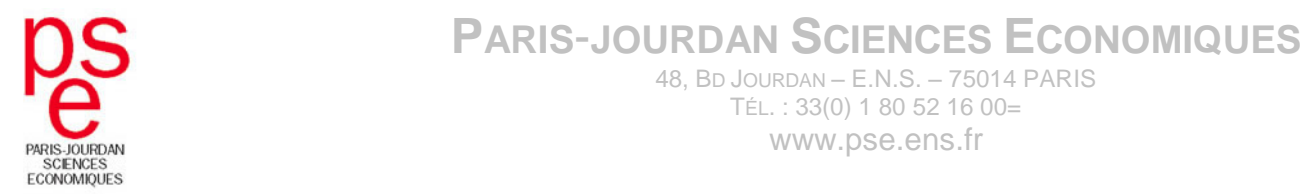




\title{
Longterm decision making under the threat of earthquakes
}

\author{
Carmen Camacho* $\quad$ Yu Sun ${ }^{\dagger \ddagger}$
}

July 1, 2017

\begin{abstract}
Under the threat of earthquakes, long-term policy makers need tools to decide optimally on the economic trajectories that maximize the society welfare. Tools should be flexible and account for the consequences of earthquakes, incorporating the best estimate of their frequency and intensity. In this regard, we propose in this paper a modeling strategy that combines optimal control techniques and Bayesian learning: after an earthquake occurs, policy makers can improve their knowledge and adjust policies optimally. Two numerical examples illustrate the advantages of our modelling strategy along different dimensions. While Japan symbolizes the policy maker who has learned from earthquakes protecting the economy accordingly; Italy helps us illustrate the importance of prevention capital.
\end{abstract}

Keywords: Bayesian Learning, Earthquakes, Prevention, Policy Making, Economic Growth.

Journal of Economic Literature: C6, O13, O21, O44, Q54.

*Paris School of Economics and Centre national de la recherche scientifique (CNRS), France. E-mail: maria.camachoperez@univ-paris1.fr

${ }^{\dagger}$ CORE and Economic School of Louvain, Université catholique de Louvain, Belgium. E-mail: y.u.sun@outlook.com

${ }^{\ddagger}$ Department of Economics, London School of Economics and Political Science, United Kingdom. 


\section{Introduction}

Major natural catastrophes like tsunamis, volcano eruptions or earthquakes entail significant human and economic losses that modify national budget constraints, productive endowments and as a consequence, economic decisions. On the 26th December 2004, 10 countries along the Indian Ocean coast were hit by an earthquake of intensity 9.3 on the Richter scale and by a subsequent tsunami. There was no warning system to inform villagers that a tsunami was approaching and 270,000 people were killed, more than 500,000 were injured and 1,8 million people were left homeless (Davis, 2008). According to the CGI (2006), main infrastructures remained largely intact but small constructions like houses, clinics, schools were destroyed explaining the high death-toll. Damage is usually explained by the poor building techniques, unadapted to earthquake activity and the low quality of the materials. We believe that another key reason is the lack of tools to build optimal economic policies in time, which would take into account the arrival and consequences of earthquakes in a wide framework. For this reason, this paper aims to enable policy makers with a tool to maximize the society well-being while optimally preparing the economy with adequate investment. Our modeling encompasses features from classic models in economic growth, together with Bayesian and adaptative learning.

There is a relative recent and growing interest on the analysis of natural catastrophes and their effects on economic growth, both in the short and the long-term. The term natural catastrophe englobes different phenomena that vary in causes and in economic and human consequences. As shown in Loayza et al. (2012), earthquakes are the natural catastrophe generating the largest economic losses; whereas droughts affect the most people. Nevertheless, some general results have been established that apply to all natural catastrophes. Developing countries suffer on average more than developed countries (Noy, 2009), economic losses are lesser for countries with higher education and greater trade openness (Toya and Skidmore, 2007) and more intense disasters produce larger negative economic impact (Fornby et al., 2013, Hochrainer, 2009, Noy, 2009, Stephens, 2007). Nevertheless, results are not unanimous regarding long-term consequences. A first group of papers defend that natural catastrophes could enhance growth in the long-run à la Schumpeter. Albala-Bertrand (1993), Stewart and Fitzgerald (2001), Okuyama (2003) and Benson and Clay (2004) find that a natural catastrophe fosters capital replacement with new, more efficient capital, which stimulates growth. In Jaramillo (2009), low income countries enjoy a medium term increase in GDP growth, 
which fades away after some years, only if the event has low incidence. Nevertheless, most papers find short and medium term losses (Raddatz, 2007, Anttila-Hughes and Hsiang, 2013, Ströbl, 2011, or Felbermayr and Gröschl, 2014) and that economies return to their growth path with time (Chhibber and Laajaj, 2008 and Klomp and Valckx, 2014).

There is also a growing number of theoretical models that highlight the role of natural catastrophes on economic growth. They allow to analyse the linkages between the natural catastrophe and the productive factors, technological progress, adaptation and mitigation policies, the role of the policy maker and public investment. There exist computable general equilibrium models, which have addressed these questions at a national scale like Shibusawa and Miyata (2011) for Japan, and at a regional level like Rose and Liao (2005). In this paper, we adopt a classical view in economic growth building a model à la Ramsey, focusing on the effects of earthquakes in the short as well as in the long-term. The closest to our approach is the NEDyM model built in the spirit of Solow (1956), developed and utilised in Hallegate and Ghil (2008) and Hallegate and Dumas (2009), for instance. Hallegate and Ghil (2008) show that natural catastrophes have a deeper effect on economies when they are booming since all resources are fully exploited. If on the contrary, the economy is at a recession, it can reallocate unexploited resources fast and in a efficient manner. Hallegate and Dumas (2009) explore whether the increase in investment that follows a natural catastrophe has an effect in the longterm. They show that since reconstruction investment comes at least partly from other national budgets, R\&D for instance, economic growth could rather slow down.

The issues of earthquake prevention and long-term optimal decision making have not been considered together so far in the literature. Nevertheless, as argued above, it seems urgent to search for models, which at the same time are flexible, comprehensive and easy to implement. Let us underline three of the main features of the present model. The main novelty and the key characteristic of our framework is the introduction of Bayesian adaptative learning. The policy maker has an estimation of the earthquake frequency and the associated damage, and she takes her optimal decisions accordingly. Standing policies are suspended upon each realisation of the earthquake and knowledge is updated. Then, the policy maker recomputes new optimal policies with revised, more accurate information on the expected frequency and intensity of earthquakes. Note that with time, the policy maker can learn the true distribution of the earthquake's frequency and intensity. Second, the original stochastic policy-making problem is transformed into a deterministic problem in which the policy maker expects earthquakes to arrive at the 
expected frequency and to hit the economy with the expected intensity. Although our model loses on instantaneous prediction precision, it does not lose in its capacity to build long-term policies. Moreover, our modelling strategy is simple to implement and it provides an accurate description of earthquakes with time. The third novelty is the modelisation of prevention capital, which encompasses all accumulated resources that protect effectively the economy against earthquakes. Prevention capital protects the economy against earthquakes, diminishes instantaneous damage after an earthquake and shortens recovery times. Its dynamics are known to policy makers, who can invest to enhance prevention or neglect it; privileging consumption and the accumulation of physical capital. In the literature, the term adaptation capital is commonly used (Ewing et al., 2003, Palecki et al., 2001). As in Ewing et al. (2003), we understand that prevention capital includes social capital, as the procedures acquired by the population to face natural catastrophes, emergency plans (ex-ante warning alerts and ex-post evacuation and aid plans), secure sewage and lifelines, the adaptation of buildings, bridges, roads, and urban planning. Noteworthy, a parallel can be established between spending in defence and in earthquake prevention. Like spending in earthquake prevention, defence enhances security, promoting productivity and economic growth (Smith, 1776). This thesis has been widely tested and corroborated ever since, see for instance Aizenman and Glick (2006), Dunne and Perlo-Freeman (2003) or Cuaresma and Reitschuler (2006).

Differently from other papers in the field of natural catastrophes, our policy maker takes into consideration the future occurrence of earthquakes using an estimation of its frequency and intensity. These qualities permit the policy maker to elaborate plans considering earthquakes while using at every moment the most updated information possible. There is varied evidence about policy makers' learning. Kalkstein and Greene (1997) find that Southern States in the US are at less risk from heat waves than Northern States, due to their longer experience. According to Palacki et al. (2011), adaptation measures count with increased policy support when frequency increases. In particular, they focus on consecutive heat waves in St. Louis, Missouri and Chicago, finding that mortality was reduced between the heat waves of 1995 and 1999. From a theoretical perspective, different learning mechanisms can be considered ranging from the businessas-usual policy maker who does not include the natural catastrophe in his planning program, to the policy maker who uses the most updated information available averaging all registers. In the mid-point, there are myopic policy makers who neglect all past information and prudent policy makers, who incorporate new information but do not assign the same importance to new event as to old registered information (see Bréchet 
et al., 2011, and Bréchet et al., 2014, for two applications ).

This paper is structured as follows. Section 2 makes a brief introduction to earthquakes. Section 3 presents a model for optimal inter temporal decision making for an economy frequently hit by earthquakes. Optimal decisions depend then on the evolution of physical and prevention capitals, both suffering from earthquakes. Beforehand, we devote a subsection to the choice of the damage function, which depends here on the catastrophe intensity and time elapsed since last occurrence, and it includes a recovery function. Both damage and recovery depend crucially on prevention. Section 4 closes this analysis developing numerically some case studies.

\section{A brief introduction to earthquakes}

An earthquake is the detectable tremor of the Earth surface. The moving plates that cover the earth find opposition in the neighbouring plates, generating frictions, until one of the plates gives in. Then, the amassed energy is released producing an earthquake immediately. ${ }^{1}$

Large earthquakes induce damages which include human life losses, infrastructure and building collapse, fires, soil liquefaction, landslides, avalanches, floods and tsunamies. According to its strength, earthquakes intensity is measured using two main scales: the Mercali and the Richter scales. In this paper, the Richter scale is privileged (see Table 5 in the Appendix for details). Earthquake intensity in the Richter scale ranges from 1 to 9, and for every unit increase in the scale, energy released increases roughly thirtyfold. According to the U.S. Geological Survey Earthquake Hazards Team, and as shown in table 6 in the Appendix, there are between 15,000 and 32,000 earthquakes worldwide every year, all intensities together. Minor earthquakes that do not entail human nor economic losses, occur almost constantly in places like California, Alaska, El Salvador, Mexico, Turkey or Japan, but they can occur everywhere. Regarding high intensity earthquakes, there has been only one earthquake of magnitude larger than 8 from 2009 to 2011 , and 2 in 2012.

Table 1 below lists the ten most intense earthquakes in history, showing the economic and human losses involved. The second largest earthquake hit Alaska in 1964, but despite its intensity it did not entail large economic losses, and only 131 people

\footnotetext{
${ }^{1}$ Although we consider here only earthquakes having a natural origin, mine blasts and nuclear tests can also generate earthquakes.
} 
lost their lives. Several reasons can explain this somehow lucky outcome. First, the earthquake happened a Good Friday so that public buildings and schools were closed. Second, Alaska has a low population density. Indeed, in 1964 and according to Pipkin and Trent (1997), population density in Alaska was less than one person per square kilometer. In the same line, the 1952 Kamchatka earthquake, the 5th most intense in history, did not take human lives and economic losses were relatively low. The Honshu earthquake of 2011 had the same intensity as the Kamchatka earthquake. In contrast to the Russian experience, 15,703 people died in Honshu and economic losses exceeded 300 billion dollars, and this despite the preparedness of the Japanese population and government.

\begin{tabular}{|l|l|l|l|l|l|}
\hline No. & Location & Date & Magnitude & $\begin{array}{l}\text { Economic } \\
\text { Loss }\end{array}$ & Fatalities \\
\hline 1 & Chile & 22.05 .1960 & 9.5 & $\$ 550$ million & 1,655 \\
\hline 2 & Alaska & 28.03 .1964 & 9.2 & $\$ 311$ million & 131 \\
\hline 3 & Northern Sumatra & 26.12 .2004 & 9.1 & $\$ 10$ billion & 227,898 \\
\hline 4 & Honshu, Japan & 11.03 .2011 & 9.0 & $\$ 309$ billion & 15,703 \\
\hline 5 & Kamchatka, Russia & 04.11 .1952 & 9.0 & $\$ 800,000$ & 0 \\
& & & & $-\$ 1,000,000$ & \\
\hline 6 & Maule, Chile & 27.02 .2010 & 8.8 & $\$ 30$ billion & 523 \\
\hline 7 & Ecuador-Colombia & 31.01 .1906 & 8.8 & n.a. & $500-1500$ \\
\hline 8 & Rat Islands, Alaska & 04.02 .1965 & 8.7 & $\$ 10,000$ & n.a. \\
\hline 9 & Northern Sumatra & 28.03 .2005 & 8.6 & n.a. & 1,000 \\
\hline 10 & Assam, Tibet & 15.08 .1950 & 8.6 & n.a. & 780 \\
\hline
\end{tabular}

Table 1: 10 Largest Earthquakes in History ${ }^{2}$

It seems clear then that some countries would need to include earthquakes in their long-term economic decision making if they aim at maximising the country's welfare. This would require precise knowledge on earthquake arrival times, on generated instantaneous damage, recovery times but also on the dynamics of prevention. All these depend in turn on the country's geographical situation, population and industrial distributions, on its administration as well as on its sensitivity to earthquakes. The following examples help us illustrate the idiosyncratic nature of earthquakes and their damage, which should be respected in this type of framework. Using data from the US National

\footnotetext{
${ }^{2}$ Based on National Centers for Environmental Information of NOAA (U.S.). Retrieved from http://earthquake.usgs.gov/earthquakes/world/10_largest_world.php
} 
Oceanographic and Atmospheric Administration (NOAA), Figure 1 displays the number of earthquakes by intensity and damage categories suffered in Japan and Italy as from $1900^{3}$. Note that although Italy has suffered less earthquakes overall and of a lower intensity than Japan, damage is relatively higher. Looking at Japan, Figure 2 highlights that most earthquakes are without effect, underlining that the country has been implementing effective prevention policies for long. In the numerical exercises of section 4 , the roles of learning and earthquake sensitivity together with prevention capital and technology are examined for these two countries.
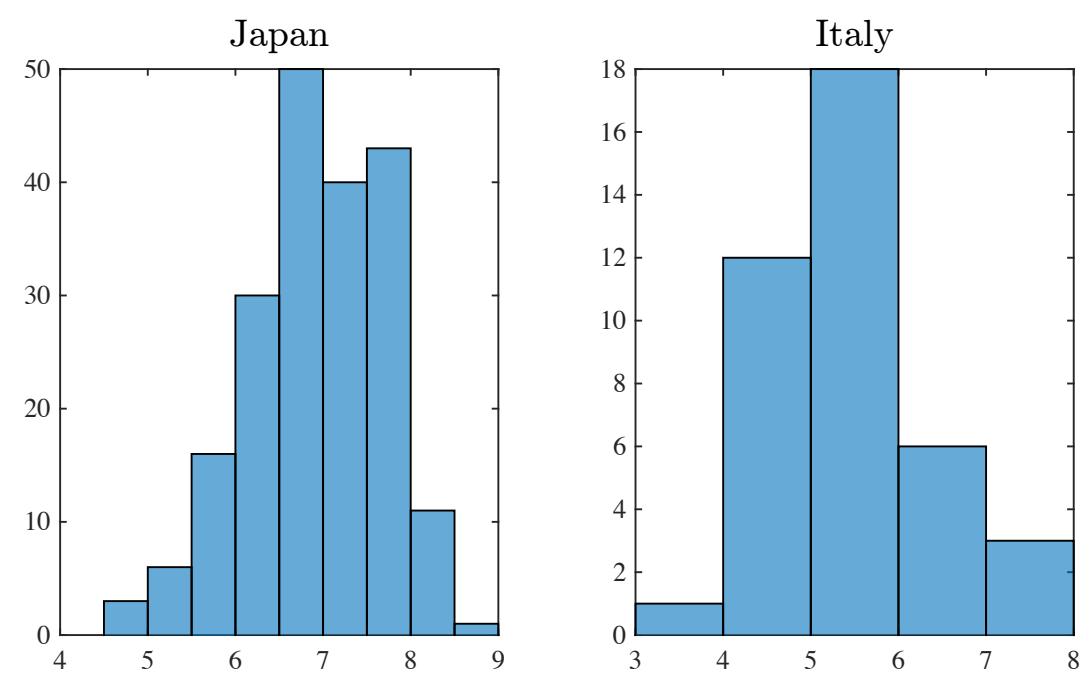

Figure 1: Number of Earthquakes by intensity. Source: NOAA.

\footnotetext{
${ }^{3}$ The damage scale is produced by the NOAA and has 4 levels. An earthquake of level 0 has no damage. A level 1 earthquake has an economic damage of less than 1 million US dollars. Level 2 earthquakes are labelled moderate and they induce a loss ranging from 1 to 5 million US dollars. Level 3 earthquakes are severe and induce losses from 5 to 24 million US dollars. Level 4 earthquakes are extreme and generated losses are larger than 25 million dollars.
} 



Figure 2: Earthquake Intensity Histogram. Source: NOAA.

Once the significance of earthquakes emphasised, the next question is how to introduce earthquakes into a long-term decision making model. Hence, we need to make assumptions on the nature and behaviour of earthquakes. In this regard, let us underline that although earthquakes have been analysed for more than 130 years, earthquake prediction has been fruitless (Mulargia et al., 2017), that is, it is impossible to forecast in the medium or long-term the occurrence of earthquakes. Nevertheless, there exist two well-established laws governing earthquakes. First, the Omari law (1894) forecasts the decay of earthquake aftermath. Second, the Gutenberg-Richter (1956) law establishes a relationship between the number of earthquakes and their intensity. According to this law, the more intense the earthquake, the less frequent (and vice versa). Regarding the modelling of earthquake frequency, there are different approaches. Here, we follow Kagan and Jackson (1994) and Kagan (2002). Using the Harvard catalog on earthquakes, the authors estimate long-term worldwide earthquake probabilities assuming that the distribution of earthquakes in time follows a Poisson process. Like theirs, our estimates are not earthquake predictions to be used as warnings, but as guides for economic policy making. In contrast to earthquake frequency, earthquake intensity cannot be predicted nor estimated. As a consequence, in this paper, the policy maker will adapt to the probability distribution of earthquakes of the average of observed intensities. 


\section{Inter temporal decision making under earthquake threat}

We develop a theoretical model to address the problem of a policy maker who faces intense earthquakes frequently. Although the economy may have suffered from earthquakes for a long time, the policy maker knowledge or awareness may be insufficient to provide an accurate stochastic description of the earthquake frequency, its intensity and the associated economic damage.

The remaining of this section is structured as follows. After a brief introduction to damage functions, section 3.1 presents our choices for the instantaneous damage and recovery time functions. Then, section 3.2 introduces a simple version of Bayesian learning tailored to our framework. Finally, section 3.3 ensures the existence of an optimal solution to the policy maker's problem and provides a set of necessary optimal conditions.

\subsection{The damage function}

The literature on economic losses generated by disasters is vast and ranges from applications of Input-Output methodologies (see Cochrane, 1974, Kawashima and Kauch, 1990), econometrics (West and Lenze, 1994), to computable general equilibrium models (Rose et al., 1997). Other papers aim at producing accurate estimates of immediate economic and material losses. Focusing on earthquake damage, Brookshire et al. (1997) and Kircher et al. (2006) forecast the economic short-term impact of earthquakes depending on their intensity and the region's building inventory, infrastructure exposure, relative vulnerability of built environment to ground shaking and also socio-economic wealth associated to exposed assets. Chan et al. (1998), Dunbar et al. (2002) or Chen et al. (2001) predict economic losses depending on earthquake intensity. Regarding damage modelisation, this paper relies mainly on Jaiswal and Wald (2011), who provide a loss function to evaluate immediate economic losses after significant earthquakes worldwide.

Jaiswal and Wald (2011) design a loss ratio, $r$, defined as the ratio between direct economic loss to total economic exposure. One of the many advantages of this loss ratio is that the same functional form fits all sensitive regions. An earthquake of intensity $s$ 
between 5.0 and 9.0 on the Richter scale generates an immediate loss of

$$
r(s)=\phi\left[\frac{1}{\beta} \ln \left(\frac{s}{\chi}\right)\right] .
$$

$\phi$ is the normal cumulative distribution function and $s$ is shaking intensity. $\chi$ and $\beta$ are two free parameters of the cumulative distribution function. It suffices then to estimate the regional values of $\beta$ and $\chi$ to compute the estimated loss ratio worldwide. Note that $\chi$ can be larger or smaller than $s$. If $\frac{s}{\chi}<1$, then its logarithm is negative but it results in positive damage given that $\phi$ is the normal cumulative distribution and it is positive definite.

In the current context of long-term decision making under the frequent arrival of earthquakes, the damage function also needs to account for delayed effects. Models forecasting damage generated by earthquakes do not usually consider recovery time simply because most models are static. However, recovery time itself is important because it determines overall economic losses. In as far as recovery depends at least partially on political decisions, it seems best suited a model with optimizing decision makers, who consider at the same time the economy and its structure, the earthquake random nature, its effects, recovery times and how these can be mitigated with adequate investment. There is debate on whether natural catastrophes induce long term gains or losses. The seminal paper of Albala-Bertrand (1993), predicted long-run gains after a natural catastrophe, led by an upgrade in capita à la Schumpeter. Old capital would be replaced by new, technologically more advanced capital. Other papers followed this line, like Stewart and Fitzgerald (2001), Okuyama (2003), Benson and Clay (2004), Jaramillo (2009) and Cuñado and Ferreira (2011). Note that this result is mainly driven by developing countries. Nevertheless, conclusions are nuanced when the origin of the solicited public investments is considered as in Hallegate and Dumas (2009). Indeed, the urgent investment in new capital may proceed from cuts in other budgets, like R\&D. Underlining the effect of intense hurricanes on the US from 1970 to 2005, Ströbl (2011) proves that economic growth can be reduced by 0.93 percentage points on average. Regarding tropical storms, Antilla, Hughes and Hsiang (2011) also find persistent losses of $6.7 \%$ several years after the storm. Analysing natural catastrophes in general, Raddatz (2007) finds that climate disasters are responsible for an average loss of $2 \%$ of GDP, a year after the event. According to Noy (2009), sudden-set disasters can make lose a $9 \%$ of GDP in developing countries. An intertemporal damage function should then incorporate a recovery period leading to one of the following three possible scenarios: long-run losses, recovery and long-run gains as depicted in Figure 3. In the case studies developed in sec- 
tion 4, we consider that countries go back with time to their pre-catastrophe economic situation.

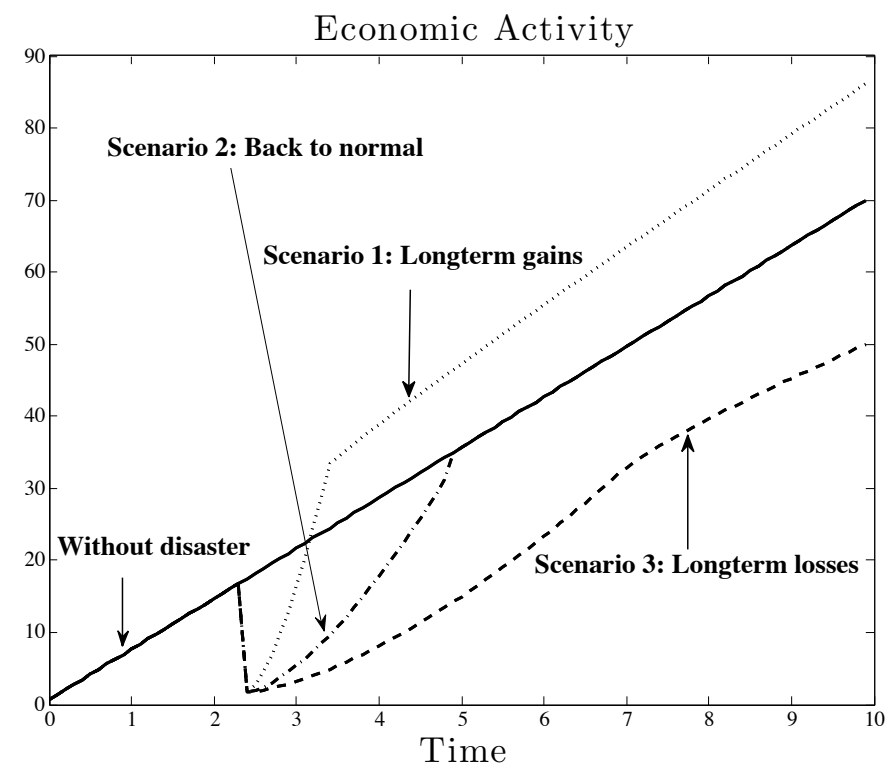

Figure 3: Recovery scenarios

Two novel additional features are added to the original loss function in Jaiswal and Wald (2011), namely investment in prevention and recovery time. First, the policy maker can invest in prevention, to protect the economy, decrease short-run losses and shorten the recovery period. In this regard, the functions describing damage and recovery do depend on prevention capital. Second, the loss function includes a recovery function $g$, which depends on prevention capital and on time elapsed since last earthquake occurrence. If the last earthquake occurred at $t^{\prime}$, the loss function at time $t$ is

$$
\varphi\left(b, \mu, t, t^{\prime}\right)=g\left(b, t, t^{\prime}\right) r(\mu)=g\left(b, t-t^{\prime}\right) \phi\left[\frac{1}{\beta} \ln \left(\frac{\mu}{\chi}\right)\right] .
$$

Function $g$ decreases in $b$ so that the larger prevention capital, the lower the loss. In the limit, $g$ converges asymptotically to zero when $b$ tends to infinite. $\varphi$ also depends time elapsed since last catastrophe and it could also encompass population density, and physical capital age. 


\subsection{Bayesian learning on earthquakes}

Here earthquakes are considered as independent realizations of a random variable, with unknown probability distribution. At a given date, the policy maker solves the optimal control problem with the available information on the random variable frequency and intensity. This means that at time 0 , the policy maker expects a realization of the variable every $\tau_{0}$ years with expected intensity $\mu_{0}$, and she incorporates the consequences to the problem. When the variable realizes, the policy maker actualises her expectations and solves again the problem. In this section we describe first Bayesian learning when the stochastic frequency of a variable follows a Poisson distribution. Then, we apply the obtained results to our particular problem. In particular, we underline the role of learning and information updating.

We assume that earthquake frequency follows a Poisson process for point processes as in Woo (1999) or Coles (2001) and as applied in Nogaj et al (2006). Indeed, as shown in Khintchine (1960), the superposition of independent processes, in which no process dominates, follows a Poisson probability distribution. The probability there will be $q$ occurrences in a time period, when the average number of occurrences in a period of time is $\gamma$ is: ${ }^{4}$

$$
p(q \mid \gamma)=\frac{\gamma^{q}}{q !} e^{-\gamma}
$$

where $\gamma, q>0$. Suppose that the average number of occurrences of a stochastic variable is unknown, that the time interval $[0, T]$ is divided in $n$ subperiods and that the aim is to compute the probability that there will be $q_{1}$ occurrences in the first subperiod, $q_{2}$ in the second subperiod, until $q_{n}$ in the last subperiod. Bayesian learning can be applied here since the probability that the average number of occurrences is $\gamma$, when there have been $\left\{q_{1}, q_{2}, \ldots, q_{n}\right\}$ occurrences in the last $n$ subperiods, equals the product of the probability of observing $\gamma$ occurrences on average over $[0, T]$, and the probability of observing $q_{i}$ in subperiod $i$ for all $i$, when the true average is $\gamma$, that is:

$$
p\left(\gamma \mid q_{1}, \ldots, q_{n}\right) \propto p\left(q_{1}, \ldots, q_{n} \mid \gamma\right) \cdot p(\gamma) .
$$

$p(\gamma)$ and $p\left(\gamma \mid q_{1}, \ldots, q_{n}\right)$ are called respectively prior and posterior probability density function. Here it is assumed that $p\left(q_{1}, \ldots, q_{n} \mid \gamma\right)$ follows a Poisson distribution, which implies that its associated prior $p(\gamma)$ follows a Gamma distribution $\gamma \sim \Gamma(1,1)$, that is

$$
p(\gamma)=e^{-\beta},
$$

\footnotetext{
${ }^{4}$ We use here the term occurrence for a realisation of the random variable. In our context, an occurrence is the realisation of an earthquake.
} 
for any $\gamma>0$. As a result, the $\gamma$ expected value and variance of $\gamma$ are $E(\gamma)=1$ and $V(\gamma)=1$. Hence, substituting (4) into (3)

$$
p\left(\gamma \mid q_{1}, \ldots, q_{n}\right) \propto \gamma^{\sum_{i=1}^{n} q_{i}} e^{-(1+n) \gamma} .
$$

Therefore, when $\left\{q_{1}, q_{2}, \ldots, q_{n}\right\}$ occurrences have been observed in the previous $n$ subperiods, the number of occurrences follows a Gamma distribution $\Gamma\left(\alpha^{*}, \beta^{*}\right)$, with

$$
\alpha^{*}=\sum_{i=1}^{n} q_{i}, \text { and } \beta^{*}=1+n .
$$

The associated conditional mean is

$$
\mathrm{E}\left(\gamma \mid q_{1}, \ldots, q_{n}\right)=\frac{1+\sum_{i=1}^{n} q_{i}}{1+n},
$$

and the corresponding conditional frequency is

$$
\Upsilon=\frac{1}{\mathrm{E}\left(\gamma \mid q_{1}, \ldots, q_{n}\right)}=\frac{1+n}{1+\sum_{i=1}^{n} q_{i}}
$$

Policy makers can be differentiated depending on their learning mechanism. Myopic decision makers actualise their beliefs on earthquake intensity using uniquely the most recent information. Others disregard current information using a conservative scheme, where they do not actualise their beliefs. These policy makers consider recent occurrences as non-significant accidents. Cautious decision makers actualize using a weighted average of past beliefs and current information. Only when all earthquake occurrences are equally weighted, the policy maker beliefs do converge to the true distribution in the long-run applying the law of large numbers.

Therefore, we shall assume that the policy maker approximates the true number of earthquake occurrences in a period of time by the average number of occurrences $\frac{\sum_{i=1}^{n} q_{i}}{n}$, with corresponding frequency is $\tau=n / \sum_{i=1}^{n} q_{i}$. Then, as time passes and the number of observations increases, the average of the number of occurrences during a given period converges to the expected value of the number of occurrences, and so estimated frequency also converges to expected frequency. We solve next the intertemporal decision problem of a policy maker who faces earthquakes frequently and who learns about them. To underline the importance of learning, we consider some scenarios in section 4, where the policy maker does not update her beliefs on earthquakes' intensity nor frequency. 


\subsection{The policy maker problem}

Suppose a risk neutral policy maker who maximizes overall discounted welfare over a finite time period in an one-sector economy made of homogeneous individuals. For simplicity, we assume population grows at a constant rate $n \in \mathbb{R}$. On a given date, welfare depends on the amount of the unique final good consumed and it is measured by a standard utility function $U$, which is a positive, increasing and concave function:

$$
U(\cdot) \geq 0, \quad U^{\prime}(\cdot) \geq 0, \quad U^{\prime \prime}(\cdot)<0 .
$$

Additionally, $U$ satisfies the Inada conditions:

$$
\lim _{C \longrightarrow 0} U^{\prime}(C)=\infty, \text { and } \lim _{C \longrightarrow \infty} U^{\prime}(C)=0 .
$$

The objective of the policy maker is to choose the trajectories for consumption and investment in physical and prevention capital that will maximize aggregated welfare of a representative agent over the time interval $[0, T]$. In that regard, the policy maker solves

$$
\max _{\{c, p\}} \int_{0}^{T} U(C(t)) e^{-\rho t} d t,
$$

where $C$ stands for consumption per capita, $c$ is the share of output devoted to consumption, and $p$ is the share of output invested in prevention capital. The policy maker discounts the future exponentially, so that parameter $\rho$ is the time discount rate. Note that the arrival of earthquakes does not modify the policy maker preferences, nor the production function. Hence although earthquakes destroy part of the output, the problem the policy maker solves does not change structurally with time.

Optimal decisions, production of the final good and earthquake damage depend on the economy's level of protection against earthquakes. To model this new investment possibility, we define prevention capital as follows:

Definition 1. Prevention capital is the aggregate of accumulated resources that protect the economy against earthquakes.

Prevention capital is then an aggregated stock made of human skills, adapted infrastructures, factories and housing (new or improved via retrofitting techniques); fire-breaks as well as national, regional and local emergency plans. Governments of all levels can invest in prevention capital, and like the Japanese government, they can even hedge insurance against catastrophes (OCDE, 2006). 
We denote by $k$ physical capital per capita and assume that production of the unique final good follows a Cobb-Douglas function with technological parameter $A$ and physical capital share $\alpha$. A share $\varphi$ of output is bygone by earthquake damage. Hence, available output for consumption and investment in physical and prevention capital is the share $(1-\varphi(b, \mu, t, \tau)) A k^{\alpha}$, which represents undamaged output.

Consumption per capita, $C(t)$, is a fraction $c$ of total undamaged output and prevention investment a fraction $p$. Hence, consumption is $C(t)=c(t)[1-\varphi(b, \mu, t, \tau)] A k^{\alpha}(t)$ and investment in prevention is $p(t)[1-\varphi(b, \mu, t, \tau)] A k^{\alpha}(t)$. Hence, the dynamic equation describing the evolution of physical capital per capita is

$$
\dot{k}(t)=[1-c(t)-p(t)][1-\varphi(b, \mu, t, \tau)] A k^{\alpha}(t)-\left(\delta_{k}+n\right) k(t) .
$$

$\delta_{k}$ is the physical capital depreciation. $b$, accumulated prevention capital per capita, evolves according to the following ordinary differential equation:

$$
\dot{b}(t)=\beta_{1}\left\{a(t)[1-\varphi(b, \mu, t, \tau)] A k^{\alpha}(t)\right\}^{\beta_{2}}-\left(\delta_{b}+n\right) b,
$$

that is, investment transforms into prevention capital via a power function, and it depreciates at a rate $\delta_{b}$. $\beta_{1}$ and $\beta_{2}$ are efficiency parameters that depend on the economy earthquake prevention skills and on the overall technology.

Let us gather all elements and describe the model the policy maker utilises at $t=0$. At the beginning of the planning horizon, the decision maker expects that an earthquake of intensity $\mu_{0}$ will arrive every $\tau_{0}$ years. We assume that the policy maker uses a CIES utility function with parameter $\sigma$, she solves the following problem:

$$
\max _{\{c, p\}} \int_{0}^{T} \frac{\left\{c(t)\left[1-\varphi\left(b, \mu_{0}, t, \tau_{0}\right)\right] A k^{\alpha}(t)\right\}^{1-\sigma}}{1-\sigma} e^{-\rho t} d t
$$

subject to

$$
\left\{\begin{array}{l}
\dot{k}(t)=[1-c(t)-p(t)]\left[1-\varphi\left(b, \mu_{0}, t, \tau_{0}\right)\right] A k^{\alpha}(t)-\left(\delta_{k}+n\right) k(t), \\
\dot{b}(t)=\beta_{1}\left\{p(t)\left[1-\varphi\left(b, \mu_{0}, t, \tau_{0}\right)\right] A k^{\alpha}(t)\right\}^{\beta_{2}}-\left(\delta_{b}+n\right) b, \text { for all } \mathrm{t} \in[0, T], \\
k(0) \text { and } b(0) \text { given. }
\end{array}\right.
$$

The state equations of the policy maker exhibit (downward) jumps at fixed dates, which correspond to the expected arrival of an earthquake: $\tau_{0}, 2 \tau_{0}, 3 \tau_{0}, \ldots$ Hence, $\dot{k}$ and $\dot{b}$ have a countable number of discontinuities and standard optimisation methods apply.

As mentioned, the optimal trajectory resulting from (7) and (8) will be applied from $t=0$ until the first earthquake arrives at time $t_{1}$. After measuring the actual 
intensity, $m_{1}$, and actual frequency $t_{1}$, the policy maker actualises her beliefs and recomputes optimal trajectories from $t_{1}$. In general, the policy maker actualises her beliefs and recomputes new optimal trajectories after each earthquake. We describe next how earthquake beliefs are actualised.

The $j^{\text {th }}$ earthquake after $t=0$ hits the economy at time $0 \leq t_{j}<T$ with intensity $m_{j}$. This $j^{t h}$ earthquake arrives then $t_{j}-t_{j-1}$ years after the last. Then, the policy maker updates first her beliefs on frequency and intensity as the average of past observations and the last:

$$
\mu_{j}=\frac{m_{j}+\sum_{i=0}^{j-1} \mu_{i}}{j} \text { and } \tau_{j}=\frac{\sum_{i=1}^{j-1}\left(t_{i+1}-t_{i}\right)+\tau_{0}}{j}=\frac{t_{j}+\tau_{0}}{j} .
$$

We know that if the policy maker updates her beliefs using the average of the observed values, as in (9), then beliefs converge towards their true values with time.

With the updated values for earthquake intensity and frequency, the policy maker solves the new problem, from $t_{j}$ :

$$
\max _{\{c, p\}} \int_{t_{j}}^{T} \frac{\left\{c(t)\left[1-\varphi\left(b, \mu_{j}, t, \tau_{j}\right)\right] A k^{\alpha}(t)\right\}^{1-\sigma}}{1-\sigma} e^{-\rho t} d t,
$$

subject to

$$
\left\{\begin{array}{l}
\dot{k}(t)=[1-c(t)-p(t)]\left[1-\varphi\left(b, \mu_{j}, t, \tau_{j}\right)\right] A k^{\alpha}(t)-\left(\delta_{k}+n\right) k(t) \\
\dot{b}(t)=\beta_{1}\left\{p(t)\left[1-\varphi\left(b, \mu_{j}, t, \tau_{j}\right)\right] A k^{\alpha}(t)\right\}^{\beta_{2}}-\delta_{b} b, \text { for all } \mathrm{t} \in\left[t_{n}, T\right] \\
k\left(t_{j}\right) \text { and } b\left(t_{j}\right) \text { given. }
\end{array}\right.
$$

At $t_{j}$, the policy maker expects the arrival of an earthquake at every $\tau_{j}$ years with an intensity of $\mu_{j}$. In other words, the state variables $k$ and $b$ are expected to receive shocks at fixed dates with known intensity at every $\tau_{j}$ years. Hence, at the moment the decision maker computes the optimal trajectory, the times of the expected shocks are $t_{j}+\tau_{j}, t_{j}+2 \tau_{j}, \ldots, t_{j}+N_{j} \tau_{j}$, where $N_{j}$ is the expected number of earthquakes from $t_{j}$ to T. $N_{j}$ is computed as the integer part of $N$ over $\tau_{j}, N_{j}=\left\lfloor\frac{T}{\tau_{j}}\right\rfloor$.

Notably, the policy maker's problem at time $t_{j}$ can be rewritten as

$$
\begin{gathered}
\max _{\{c, p\}} \sum_{i=0}^{N_{j}-1} \int_{t_{j}+i \tau_{j}}^{t_{j}+(i+1) \tau_{j}} \frac{\left\{c(t)[1-\varphi(b, \mu, t, \tau)] A k^{\alpha}(t)\right\}^{1-\sigma}}{1-\sigma} e^{-\rho t} d t \\
+\int_{t_{j}+N_{j} \tau_{j}}^{T} \frac{\left\{c(t)[1-\varphi(b, \mu, t, \tau)] A k^{\alpha}(t)\right\}^{1-\sigma}}{1-\sigma} e^{-\rho t} d t
\end{gathered}
$$


subject to

$$
\left\{\begin{array}{l}
\dot{k}(t)=[1-c(t)-p(t)]\left[1-\varphi\left(b, \mu_{j}, t-i \tau_{j}, \tau_{j}\right)\right] A k^{\alpha}(t)-\left(\delta_{k}+n\right) k(t), \\
\dot{b}(t)=\beta_{1}\left\{p(t)\left[1-\varphi\left(b, \mu_{j}, t-i \tau_{j}, \tau_{j}\right)\right] A k^{\alpha}(t)\right\}^{\beta_{2}}-\delta_{b} b(t)
\end{array}\right.
$$

for $t \in\left[t_{j}+i \tau_{j}, t_{j}+(i+1) \tau_{j}\right]$ and $i=0, \ldots, N_{j}$, with $k\left(t_{j}\right)$ and $b\left(t_{j}\right)$ known, $k(0)$ and $b(0)$ known. Abusing of notation, we identify $T=t_{j}+\left(N_{j}+1\right) \tau_{j}$. Note how the damage function evolves with time, but only inasmuch as it defines time elapsed since last earthquake, that is, recovery time. We define the set of admissible controls to problem (11)-(12) as follows:

Definition 2. A pair of control variables $\{c, p\}$ is said to be $\tau_{j}$-admissible for a given switching frequency $\tau_{j} \in[0, T]$ if

a) There exists a unique solution $\left(k^{*}, p^{*}\right)$ to (12) with $N_{j}$ shocks at times $t_{j}+\tau_{j}, t_{j}+$ $2 \tau_{j}, \ldots, t_{j}+N_{j} \tau_{j}$, with initial condition $\left(k\left(t_{j}\right), b\left(t_{j}\right)\right)$, for all $j$.

b) The pair of controls $\left\{c^{*}, p^{*}\right\}$ are measurable and bounded functions, with $0 \leq$ $c^{*}(t) \leq 1$ and $0 \leq p^{*}(t) \leq 1$, for all $t \in\left[t_{j}, T\right]$.

Theorem 1 provides the set of necessary optimal conditions:

Theorem 1. Given $t_{j}$ and the couple $\left(\tau_{j}, \mu_{j}\right)$, let us define on each interval $\left[t_{j}+i \tau_{j}, t_{j}+\right.$ $\left.(i+1) \tau_{j}\right]$, with $i=0, \ldots, N_{j}$ and $\left(N_{j}+1\right) \tau_{j}=T$, the Hamiltonians $H_{i}\left(t, k, b, c, p, \lambda_{1}^{i}, \lambda_{2}^{i}\right)$ and the co-state variables $\lambda_{1}^{i}$ and $\lambda_{2}^{i}$ as:

$$
\begin{aligned}
& H_{i}\left(t, k, b, c, p, \lambda_{1}^{i}, \lambda_{2}^{i}\right)=\frac{\left.\left\{c(t)\left[1-\varphi\left(b, \mu_{j}, t-i \tau_{j}, \tau_{j}\right)\right)\right] A k^{\alpha}(t)\right\}^{1-\sigma}}{1-\sigma} e^{-\rho t} \\
& +\lambda_{1}^{i}\left\{[1-c(t)-p(t)]\left[1-\varphi\left(b, \mu_{j}, t-i \tau_{j}, \tau_{j}\right)\right] A k^{\alpha}(t)-\left(\delta_{k}+n\right) k(t)\right\} \\
& +\lambda_{2}^{i}\left\{\beta_{1}\left\{p(t)\left[1-\varphi\left(b, \mu_{j}, t-i \tau_{j}, \tau_{j}\right)\right] A k^{\alpha}(t)\right\}^{\beta_{2}}-\left(\delta_{b}+n\right) b(t)\right\} .
\end{aligned}
$$

Assume there exists an optimal control set $\left\{c_{j}^{*}, p_{j}^{*}\right\}$ associated to $\tau_{j}$ defined on $\left[t_{j}, T\right]$. Let $\left\{c_{j, i}^{*}, p_{j, i}^{*}\right\}$ denote the restriction of $\left\{c_{j}^{*}, p_{j}^{*}\right\}$ to the time interval $\left[t_{j}+i \tau_{j}, t_{j}+(i+1) \tau_{j}\right]$ for all $i$. Then, it is necessary that there exists a couple $\left\{\lambda_{1}^{i}, \lambda_{2}^{i}\right\}$ such that $\left\{k^{*}, b^{*}\right\}$ satisfy a set of canonical equations at every $t \in\left[t_{j}+i \tau_{j}, t_{j}+(i+1) \tau_{j}\right]$ :

$$
\begin{aligned}
& \dot{k}^{*}=[1-c-p]\left[1-\varphi\left(b^{*}, \mu_{j}, t-i \tau_{j}, \tau_{j}\right)\right] A k^{\alpha *}-\left(\delta_{k}+n\right) k^{*}=\frac{\partial H_{i}}{\partial \lambda_{1}^{i}}, \\
& \dot{b}^{*}=\beta_{1}\left\{p\left[1-\varphi\left(b^{*}, \mu_{j}, t-i \tau_{j}, \tau_{j}\right)\right] A k^{\alpha *}\right\}^{\beta_{2}}-\left(\delta_{b}+n\right) b^{*}=\frac{\partial H_{i}}{\partial \lambda_{2}^{i}},
\end{aligned}
$$


and

$$
\begin{aligned}
\dot{\lambda}_{1}^{i}(t) & =-\frac{\partial H_{i}}{\partial k}=-\left\{c\left[1-\varphi\left(b^{*}, \mu_{j}, t-i \tau_{j}, \tau_{j}\right)\right] A\right\}^{1-\sigma} \alpha k^{\alpha(1-\sigma)-1} e^{-\rho t} \\
& -\lambda_{1}\left\{(1-c-p)\left[1-\varphi\left(b^{*}, \mu_{j}, t-i \tau_{j}, \tau_{j}\right)\right] A \alpha k^{\alpha-1}-(\delta+n)\right\} \\
& -\lambda_{2} \alpha \beta_{1} \beta_{2}\left\{p\left[1-\varphi\left(b^{*}, \mu_{j}, t-i \tau_{j}, \tau_{j}\right)\right] A\right\}^{\beta_{2}} k^{\alpha \beta_{2}-1}, \\
\dot{\lambda}_{2}^{i}(t) & =-\frac{\partial H_{i}}{\partial b}=\left(c A k^{\alpha}\right)^{1-\sigma}\left[1-\varphi\left(b^{*}, \mu_{j}, t-i \tau_{j}, \tau_{j}\right)\right]^{-\sigma} \varphi_{b}^{\prime}\left(b^{*}, \mu_{j}, t-i \tau_{j}, \tau_{j}\right) e^{-\rho t} \\
& +\lambda_{1}(1-c-p) \varphi_{b}^{\prime}\left(b^{*}, \mu_{j}, t-i \tau_{j}, \tau_{j}\right) A k^{\alpha} \\
& +\lambda_{2}\left\{\beta_{1} \beta_{2}\left[p A k^{\alpha}\right]^{\beta_{2}} \varphi_{b}^{\prime}\left(b^{*}, \mu_{j}, t-i \tau_{j}, \tau_{j}\right)\left(1-\varphi\left(b^{*}, \mu_{j}, t-i \tau_{j}, \tau_{j}\right)\right)^{\beta_{2}-1}+\delta_{b}+n\right\},
\end{aligned}
$$

with $\left\{k\left(t_{j}\right), b\left(t_{j}\right)\right\}$ known. The optimal values for the control variables are the solutions to

$$
\begin{aligned}
\frac{\partial H_{i}}{\partial c_{j, i}^{*}} & =0 \Rightarrow c_{j, i}^{*}=\frac{\left(\lambda_{1}^{i} e^{\rho t}\right)^{-1 / \sigma}}{(1-\varphi(b, \mu, t, \tau)) A k^{\alpha}}, \\
\frac{\partial H_{i}}{\partial p_{j, i}^{*}} & =0 \Rightarrow p_{j, i}^{*}=\left(\frac{\lambda_{2}^{i} \beta_{1} \beta_{2}}{\lambda_{1}^{i}}\right)^{\frac{1}{1-\beta_{2}}} \frac{1}{(1-\varphi(b, \mu, t, \tau)) A k^{\alpha}},
\end{aligned}
$$

for all $i$. Furthermore, the following matching conditions are satisfied:

$$
\begin{aligned}
& \lambda_{1}^{i *}\left(t_{j}+(t+1) \tau_{j}\right)^{-}=\lambda_{1}^{(i+1) *}\left(t_{j}+(t+1) \tau_{j}\right)^{+}, \\
& \lambda_{2}^{i *}\left(t_{j}+(t+1) \tau_{j}\right)^{-}=\lambda_{2}^{(i+1) *}\left(t_{j}+(t+1) \tau_{j}\right)^{+},
\end{aligned}
$$

and

$$
\lim _{t \rightarrow\left(t_{j}+(t+1) \tau_{j}\right)^{-}} H_{i}\left(t, k, b, c, p, \lambda_{1}^{i}, \lambda_{2}^{i}\right)=\lim _{t \rightarrow\left(t_{j}+(t+1) \tau_{j}\right)^{+}} H_{i+1}\left(t, k, b, c, p, \lambda_{1}^{i+1}, \lambda_{2}^{i+1}\right) .
$$

Theorem 1 provides a method to compute the optimal trajectories for the economy after each earthquake. Note that trajectories computed at $t_{j}$ will be applied from $t_{j}$ until $t_{j+1}$, the arrival time of next earthquake. We shall define the optimal trajectory for the time interval $[0, T]$ as the juxtaposition of the optimal solutions between two earthquakes. If there are $\mathcal{N}$ earthquakes during the time interval $[0, T]$, we denote by $t_{\mathcal{N}}$ the arrival time of the last earthquake and define $t_{\mathcal{N}+1}=T$. Hence, the policy maker re-computes $\mathcal{N}$ times the optimal trajectory over the periods $\left[t_{j}, T\right]$ to build the optimal policy for the entire period. The resulting optimal solution is the juxtaposition of the optimal solution between two earthquakes:

Definition 3. The optimal solution to problem (7)-(10) is a set $\left\{k^{*}, b^{*}, c^{*}, p^{*}\right\}$, con- 
structed piece wisely:

$$
\begin{aligned}
& k^{*}(t)=k_{j}^{*}\left(t+t_{j}\right), \\
& b^{*}(t)=b_{j}^{*}\left(t+t_{j}\right), \\
& c^{*}(t)=c_{j}^{*}\left(t+t_{j}\right), \\
& p^{*}(t)=p_{j}^{*}\left(t+t_{j}\right),
\end{aligned}
$$

for $t \in\left[t_{j}, t_{j+1}\right], j=0, \ldots, \mathcal{N}$, and where $\left\{k_{j}^{*}, b_{j}^{*}, c_{j}^{*}, p_{j}^{*}\right\}$ is the optimal solution computed after the $j^{\text {th }}$ earthquake.

\section{Numerical case studies.}

In this section, the roles of learning and prevention capital are analysed numerically and their consequences are measured. We have chosen two countries that are afflicted by earthquakes frequently, namely Japan and Italy. As shown in Figure 2 in section 2 , the two countries do not suffer equally from comparable earthquakes. This reflects differences in preparedness, which, in light of our model, stem from varying knowledge on earthquakes and their structural capacity to protect the economy. We have identified each country with an initial level of prevention capital, and run simulations under a number of scenarios that contrast the benchmark results. On the one hand, Japan is the perfect example of learning and prevention since the country's behaviour reflects a deep knowledge of earthquake frequency and intensity. Indeed, the long history of enormous and necessary Japanese investment in prevention capital protects the economy and minimises loses. On the other hand, evidence suggests that Italy does not posses an effective level of prevention capital.

Let us present first the calibration method and then the associated results for each country in two separated subsections. Data on earthquakes' intensity, date and exact location are collected from the NOAA. Data on GDP and population are extracted from the World DataBank in the World Development Indicators Database. Japan learning period is fixed to 1990-2000 and Italy's to 1980-2000. All numerical exercises cover the years 2000 to 2015 .

The model has two functional forms to specify and calibrate. The first of these functions is the production function, which we assume is of the Cobb-Douglas type. Although the benchmark model of section 3 does not consider any engine of exogenous technological progress, it is needed to reproduce Japan's GDP trajectory. For simplicity 
reasons, exogenous technological progress is assumed to be a linear function of time, so that the production function in per capita terms is:

$$
f(k)=(A+\gamma t) k^{\alpha}
$$

Output is initialized using 2000 data by the World DataBank in the World Development Indicators Database. Hence, we need to calibrate $A, \gamma$ and $\alpha$ so that $y(0)=(A+\gamma t) k(0)^{\alpha}$ coincides with the countries output, and that national output grows at the observed rate over the 15 years of the simulation exercise. Table 2 collects the calibrated values for the model parameters. Note that for Italy, we only reproduce those parameters whose calibration differs from Japan's.

\begin{tabular}{llll} 
& & Japan & Italy \\
\hline$A$ & Scale parameter & 0.6 & \\
$\alpha$ & Output elasticity & 0.75 & \\
$\gamma$ & Time trend & 0.001 & 0 \\
$\sigma$ & Utility parameter & 0.6 & \\
$\rho$ & Time discount rate & 0.015 & \\
$\delta_{k}$ & $k$ depreciation rate & 0.004 & \\
$n$ & Population growth rate & -0.015 & 0 \\
$\beta_{1}$ & Prevention skills production parameter & 0.75 & \\
$\beta_{2}$ & Prevention skills production parameter & 0.5 & \\
$\delta_{b}$ & $b$ depreciation rate & 0.01 & \\
\hline
\end{tabular}

Table 2: Calibration of the state equations

Next, the final form of the damage function is

$$
\varphi\left(b, \mu, t, t^{\prime}\right)=g\left(b, t-t^{\prime}\right) \phi\left[\frac{1}{\beta} \ln \left(\frac{\mu}{\chi}\right)\right]=\frac{z}{b(t)} e^{\Omega(\mu-m)^{\theta_{1}}} e^{-\left(t-t^{\prime}\right)^{\theta_{2}} \phi}\left[\frac{1}{\beta} \ln \left(\frac{\mu}{\chi}\right)\right] .
$$

The above specification for $g$ encompasses all required features. That is, it decreases with $b(t)$ and time elapsed since last earthquake. Additionally, damage depends on the estimation error of the policy maker regarding intensity via the term $e^{\Omega(\mu-m)^{\theta_{1}}}$.

Under the calibration for Japan, whenever $b(0)=k(0)$, that is, if Japan had as much prevention capital as physical capital, then there are almost no losses after an earthquake. When $b(0)=0.1 k(0)$, then the economic losses generated if an earthquake of intensity $\mu$ hit at $t=0$ would be $1.5 \%$ of the initial production. The electronic 


\begin{tabular}{llll} 
& & Japan & Italy \\
\hline$b(0)$ & Initial prevention capital & $0.1 k(0)$ & $0.0005 k(0)$ \\
$z$ & Recovery function parameter & $10^{5}$ & $10^{6}$ \\
$\Omega$ & Recovery function parameter & 0 & 5 \\
$\theta_{1}$ & Recovery function parameter & 0 & 0.01 \\
$\theta_{2}$ & Recovery function parameter & 2 & \\
$\beta$ & Damage function parameter & 0.1 & \\
$\chi$ & Damage function parameter & 10.291 & 9.03 \\
\hline
\end{tabular}

Table 3: Damage function calibration.

database associated to Jaiswal and Wald (2011) provides the most recent estimations for the parameters in the loss ratio $\phi$, as displayed in Table 3.

Using historical data, we have computed the average of frequency and intensity related to earthquakes of intensity larger than 5 to act as initial condition for the simulation period, which covers the years 2000-2015. The resulting initial expected frequencies and intensities are displayed in Table 4.

\begin{tabular}{llll} 
& & Japan & Italy \\
\hline$\tau_{0}$ & Initial expected frequency & 0.5 & 1.33 \\
$\mu_{0}$ & Initial expected intensity & 6.6 & 5.15 \\
\hline
\end{tabular}

Table 4: Initial beliefs.

The last element to calibrate is the initial value of prevention capital. This initial value describes the state of the art of the country's preparedness to face earthquakes and to protect the economy. In the benchmark scenario for Japan initial prevention capital is equivalent to $10 \%$ of its physical capital. With this initial prevention capital, Japan loses at most a $1.5 \%$ of its GDP upon an earthquake of intensity larger than 6 , being this loss distributed in time. Italy's initial prevention capital is calibrated to be $0.05 \%$ of physical capital, which is a very low level. There are reasons to believe that most Italian infrastructures and public/private buildings, schools, etc. are not optimally adapted for earthquakes. In a 2006 study after the Potenza earthquake, all buildings in the region were analysed. Although the law enforces earthquake resistant buildings for new buildings after 1980, resistant buildings account only for $35 \%$ of the total, and mainly in urban areas. However, over the last 20 years, earthquakes have hit 
the countryside and the Italian mountains.

\subsection{Japan, the good learner.}

From 2000 to 2015 Japan has suffered 55 earthquakes. Data show that earthquakes of intensity lower than 8 hardly provoke any damage. This is the result of sustained investment in prevention since long date. As our numerical results show, Japan has been learning from earthquakes for so long that their knowledge is almost perfect. As a result, their policies would follow the same lines even if they stopped learning today.

The numerical exercises for Japan start with the case in which there is no learning about the earthquake intensity nor about its frequency. They are followed by the exercises in which the policy maker learns about the earthquake, assigning to expected frequency and intensity the average of the observed values. In each of these sets of exercises the role of prevention is underlined considering two initial levels of prevention capital, corresponding to a good and an insufficient level, respectively.
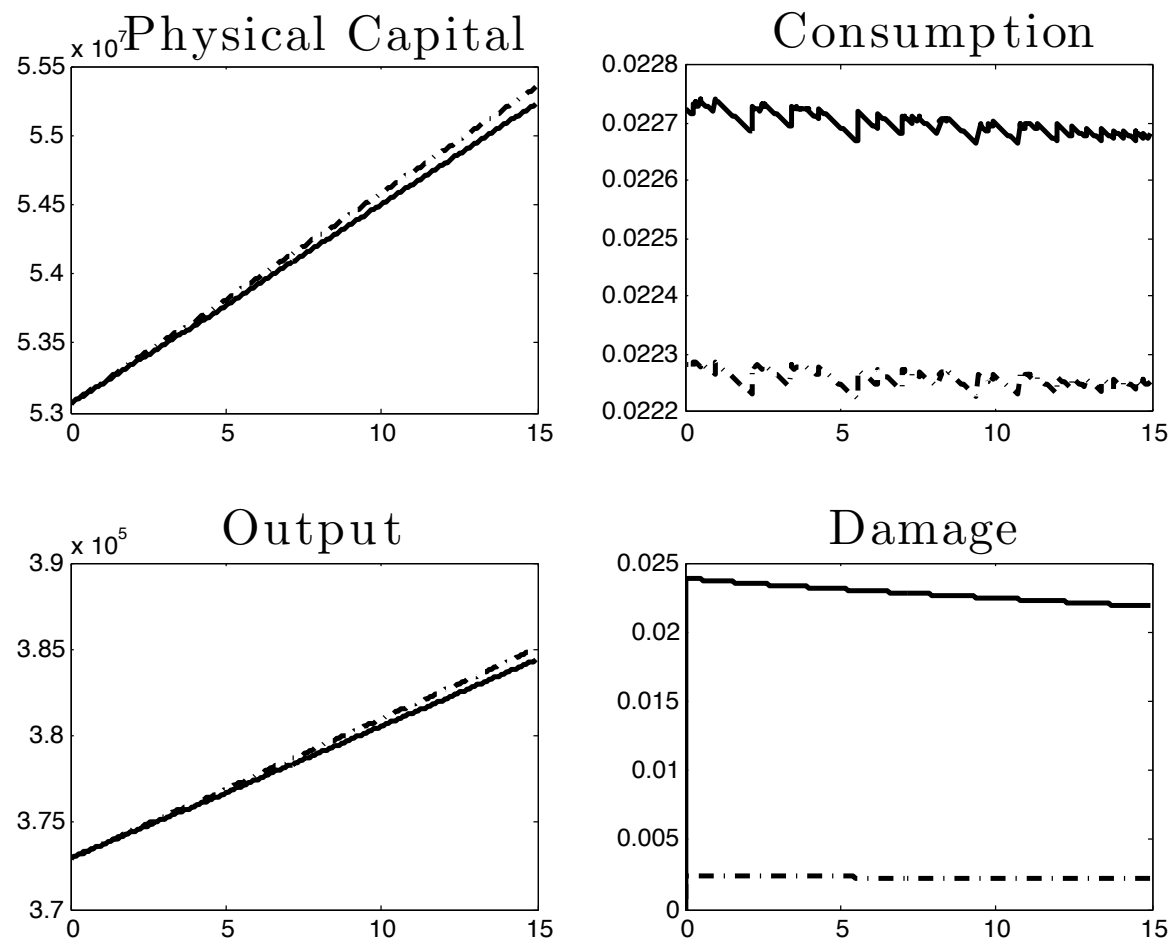

Figure 4: Japan, no learning. Solid lines: $b(0)=0.01 k(0)$. Dash-dotted: $b(0)=0.1 k(0)$. 
Figure 4 shows the numerical results for the first exercises, with no learning. As mentioned in the calibration section, when Japan starts with a prevention capital that is $10 \%$ of its physical capital stock (dashed lines), damage is low. Japan would lose less than $0.25 \%$ of its GDP on a continuous basis. Note the small figure for a country hit by 55 earthquakes in 15 years with an average intensity of 6.6. At the 15 year aggregate, an earthquake of intensity 6 generates at most a loss of $1.5 \%$ of Japanese GDP (if no other earthquake hits before). However, if Japan started with ten times less prevention capital (solid lines), then loses would amount to $2.5 \%$ of its production due to the accumulated effect of earthquakes. That is, Japan would lose 5 times more of its production if it was poorly protected against earthquakes. Note that damage decreases slightly with time because prevention capital increases in the 15 years of the simulation. Besides the role of prevention capital in growth, the Japanese economy recovers after an earthquake stimulated by the undamaged exogenous technological progress, as shown by the pictures of physical capital and output in Figure 4. Prevention capital also has an impact on GDP growth even in this case, where the damage induced by earthquakes is low. GDP overall growth rate during the period 2000-2015 is of $3.25 \%$ in the high prevention capital benchmark, and $3.08 \%$ in the case with ten times less prevention capital. Worth to underline, GDP and physical capital trajectories diverge with time, and their differences increase with time. That is, as if damage to GDP and capital was accumulating, despite that damage does not affect the stock, but the production flow.

As in the original Ramsey (1928) model, the policy maker choices result in a smooth trajectory for consumption with small downward jumps caused by earthquakes. The share of GDP devoted to consumption is larger when prevention capital is low. The average household consumes around $2.27 \%$ of annual GDP when prevention is poor compared to an average of $2.225 \%$ when better protected. Although this result may seem strange at first, it is not so if one thinks that investment in prevention also needs resources to be maintained and to eventually increase. Hence, the larger prevention capital, the more resources the economy needs to devote to prevention, even if it is just to maintain the level of prevention capital. Since earthquakes do not modify the policy maker's preferences, the consumption trajectories associated to the low and high prevention capital are qualitatively identical. We observe that both trajectories oscillate around an average value. Earthquakes shift consumption downwards showing that to reduce consumption is the policy maker's main tool to face economic losses. Indeed, among the three uses of production: consumption, investment in physical or prevention capital, it is consumption that absorbs most of the losses generated by earthquakes. This 
result deserves some comments. Consumption defines welfare, so one does not expect that a policy maker sacrifices consumption to privilege physical capital. Nevertheless, if everything else remains equal, sacrifices in consumption do not accumulate in time. That is, they do not have further negative consequences. On the contrary, reductions in investment in physical or prevention capital do have lasting effects on the future of production and consequently on future consumption. Upon an earthquake, the policy maker sacrifices today's consumption to preserve tomorrow's.

Then, earthquake intensity learning is introduced. Numerical results show little differences between the exercises with and without learning on earthquake intensity. For the sake of brevity we do not show here the numerical results of this exercise since they resemble results in Figure 4. This outcome teaches us one important lesson. When countries have acquired sufficient experience on earthquakes, devoting extra effort to learning is rewardless. And this is notably the case of Japan. Japan has been preparing for earthquakes for long, adapting infrastructures and designing mixed private-public insurance mechanisms (OCDE, 2006).

Our results can be briefly summarised in three main conclussions. First, prevention capital protects the economy and can generate important differences in GDP growth in the medium term. Second, when an earthquake hits the economy, the policy maker main tool to re-equilibrate the economy is to sacrifice the period's consumption. This allows the policy maker to maintain the level of the stocks of physical and prevention capital, which ensure future welfare. And third, when policy makers accumulate accurate knowledge on earthquakes, making further efforts does not transcend in higher welfare nor in larger GDP.

\subsection{Italy. A historical country made of stone}

Italy has suffered 25 earthquakes from 1980 to 2015, with an average intensity of 5.44 in the Richter scale. The largest earthquake during those 35 years happened in April 2009 in the region of L'Aquila in the center of the country.

Time is represented on the horizontal axis of Figure 5 , so that $t=0$ corresponds to year 2000. We have run two exercises for Italy. In the first exercise, the benchmark, prevention capital is as low as $0.05 \%$ of physical capital and the policy maker does not update her beliefs on earthquake intensity nor frequency. In a second exercise, we consider that Italy mimics Japan, that is, that its initial prevention capital is $0.1 \%$ of 



Figure 5: Italy.

the initial physical capital and that the policy maker collects information after each earthquake occurrence to update her beliefs. Figure 5 shows the resulting trajectories for consumption and output. As observed in the previous exercise on Japan, the policy maker adapts to the shocks using the period consumption. Indeed, we observe relative large fluctuations in consumption that help preserving investment in future capital and hence future consumption. Next, we consider a second scenario in which Italy updates its beliefs on earthquake intensity and frequency, and it had the same relative initial stock of prevention capital as Japan. Results correspond to the solid lines in Figure 5. Broadly speaking, we can conclude that prevention capital enhances consumption. Take consumption after the November 2004 earthquake of Salo in Lombardy. Note how to maintain a high level of prevention capital, the well protected Italy decreases consumption further than the unaware Italy. Since the economy is better protected, the effects of the earthquake last shorter. As a result, production grows faster enhancing later consumption. This corresponds to the peak in consumption at $t=10$ or year 2010 .

There is a very interesting phenomenon after 2005. From 2002 to 2005, there was a series of 5 earthquakes. The economy had not completely recovered from the previous earthquake when a new earthquake arrived. As a result, damage accumulated. Besides, the policy maker did not change her beliefs or her view on prevention capital, so that she was privileging consumption. As a consequence, output declines between 2005 and 2009 . Then in 2009, output starts increasing. Indeed, following a period of more than 4 years 
of an austere consumption regime, the 2009 earthquake reduces further consumption. This time the policy maker privileges investment in physical capital and re-launches the final good sector. Indeed, after the 2009 earthquake of L'Aquila of intensity 6.3 the economy starts growing again, although at a lower rate than the well-protected economy. Three years later, another earthquake of intensity 6.1 arrives at Emilia-Romagna and destroys an important share of production. Consumption adjusts and output continues increasing, but at an even lower rate. Once again, the economy did not have time to recover, and it accumulates damage. In particular, had the economy be better protected, output would have increased a $2 \%$ more.

Three main results should be underlined. First, an economy which disregards the role of prevention capital does not diminish consumption as much as a better protected economy after an earthquake. Second, in poorly protected economies with no learning, earthquakes may have everlasting consequences on consumption, output and economic growth. Third, damage from a series of close earthquakes accumulates, being magnified upon each new arrival.

\section{Conclusions}

We have developed a modelling strategy to build optimal and flexible policies in time for economies frequently hit by earthquakes. Our framework allows the policy maker to learn and improve her knowledge on the stochastic nature of earthquakes as well as to invest in prevention to lessen the effects of earthquakes. Other novelties include a damage function which comprehends recovery time, the crucial time period after each earthquake.

Section 3 provides a practical description of the set of optimal necessary conditions that will be applied after each earthquake. When an earthquake hits the economy, the policy maker interrupts the on-going policies and obtains information about its frequency and intensity. Then, new policies are computed and applied. The overall optimal trajectory is then the juxtaposition of optimal policies between earthquake occurrences. Our numerical examples help us illustrate key elements in this decision problem: the initial level of prevention capital, the roles of technology and economic growth, of earthquake information and of awareness. The case studies of Japan and Italy have illustrated our modelling strategy. Overall, our numerical results have shown how prevention capital and accurate earthquake information not only protect better the 
economy, but also increase consumption, long-term economic growth, enhancing welfare.

There are many extensions we consider for future work. First, the damage function would need further research to obtain a more accurate calibration of extreme earthquakes as well as of inter temporal damages. One of the most challenging and demanding projects is to allow the policy maker's preferences vary with damage directly and not just via reductions in consumption. Then, in a second set of extensions, we would like to build a model considering together general natural catastrophes, global warming and economic growth as an extension of integrated assessment models à la Nordhaus (1991). Finally, the extension of the present model to an economy population with heterogenous agents to analyse the impact of natural catastrophes on inequality.

\section{References}

Aizenman, J. and Glick, R. (2006), "Military expenditure, threats, and growth", Journal of International Trade Es Economic Development, 15, 129-155.

Albala-Bertrand, J. M. (1993), "Natural disaster situations and growth: A macroeconomic model for sudden disaster impacts", World Development, 21(9), 1417-1434.

Anttila-Hughes, J. K. and S. M. Hsiang (2013), "Destruction, disinvestment, and death: Economic and human losses following environmental disaster". SSRN 2220501.

Benson, C. and E. J. Clay (2004), "Understanding the economic and financial impacts of natural disasters", World Bank Publications.

Bréchet, T., C. Camacho and V., M. Veliov, (2014), "Adaptive Model-Predictive Climate Policies in a Multi-Country Setting", in The Oxford Handbook of the Macroeconomics of Global Warming, Oxford University Press.

Bréchet,T., C. Camacho and V. M. Veliov, (2011), "Model predictive control, the economy, and the issue of global warming", Annals of Operations Research, Volume 220, Issue 1, 25-48.

Brookshire, D. S., S.E. Chang, H. Cochrane, R. A. Olson, A. Rose and J. Steenson, (1997), "Direct and Indirect Economic Losses from Earthquake Damage", Earthquake Spectra, 13(4), 683-701.

CGI (2006), The 15th Meeting of The Consultative Group on Indonesia, Jakarta, June 14, 2006, Preliminary Damage and Loss Assessment Đ Yogyakarta and Central Java Natural Disaster.

Chan, L. S., Y. Chen, Q. Chen, J. Liu, W. Dong and H. Shah (1998), "Assessment of global seismic loss based on macroeconomic indicators", Natural Hazards, 17, 269-283. 
Chen, Y., Q. Chen and L. Chen (2001), "Vulnerability analysis in earthquake loss estimate", Natural Hazards, 23, 349-364.

Chhibber, A. and R. Laajaj (2008), "Disasters, climate change and economic development in sub-Saharan Africa: lessons and directions", Journal of African Economies, 17.

Cochrane, H. C. (1974), "Predicting the Economic Impact of Earthquakes", Institute of Behavioural Science, University of Colorado, Working Paper, No.15.

Coles, S. (2001), An Introduction to Statistical Modeling of Extreme Values, Springer, New York.

Cuaresma, J.C. and Reitschuler, G. (2006), "Gun or better? Revisited. Robustness and nonlinearity issues in the defense-growth nexus", Scottish Journal of Political Economy, 4, 523-541.

Davis, L. (2008), Natural Disasters, Facts on File, New York.

Dunbar, P., R. Bilham and M. Laituri (2002), "Earthquake loss estimation for India based on macroeconomic indicators", in Beer, T., and Ismail-Zadeh, A., eds., Risk science and sustainability? Science for reduction of risk and sustainable development of society, Dordrecht, Kluwer Academic Publishers, 163-180.

Dunne, P. and Perlo-Freeman, S. (2003), "The Demand for Military Spending in Developing Countries", International Review of Applied Economics, 17, 23-48.

itemEwing, B.T., J.B. Kruse and M.A. Thompson (2003), "A comparison of employment growth and stability before and after the Fort Worth tornado", Environmental Hazards, 5, 83-91.

Felbermayr, G. and J. Groschl (2014), "Naturally negative: The growth effects of natural disasters", Journal of development economics, 111, 92-106.

Fomby, T., Y. Ikeda, and N. V. Loayza (2013), "The growth aftermath of natural disasters," Journal of Applied Econometrics, 28, no. 3, 412-434.

Gutenberg B. and C.F. Richter (1956), "Magnitude and energy of earthquakes", Annals of Geophysics, 9, pp. $1 Đ 15$.

Hallegatte, S. and M. Ghil (2008), "Natural disasters impacting a macroeconomic model with endogenous dynamics", Ecological Economics, 68(1), 582-592.

Hallegatte, S. and P. Dumas (2009), "Can natural disasters have positive consequences? Investigating the role of embodied technical change", Ecological Economics, 68(3), 777-786. 
Hochrainer, S. (2009), "Assessing the macroeconomic impacts of natural disasters: are there any?", World Bank Policy Research Working Paper Series, Vol. 2009.

Loayza, N. V., E. Olaberria, J. Rigolini and L. Christiaensen (2012), "Natural disasters and growth: Going beyond the averages", World Development, 40(7), 1317-1336.

Jaiswal, K.S. and D.J. Wald (2011), "Rapid estimation of the economic consequences of global earthquakes", U.S. Geological Survey, 47, 2011-1116.

Jaramillo, H. (2009), "Do natural disasters have long-term effects on growth?", Documentos CEDE.Universidad de los Andes, Bogotá, D. C., Colombia.

Kagan, Y. Y., and D. D. Jackson (1994), "Long?term probabilistic forecasting of earthquakes," Journal of Geophysical Research: Solid Earth, 99.B7, 13685-13700.

Kagan, Yan Y. (2002), "Seismic moment distribution revisited: I. Statistical results," Geophysical Journal International, 148.3, 520-541.

Kalkstein, L. S. and J. S. Greene (1997), "An evaluation of climate/mortality relationships in large US cities and the possible impacts of a climate change", Environmental health perspectives, $105(1), 84$.

Kawashima, K. and T. Kanoh (1990), "Evaluation of Indirect Economic Effects Caused by the 1983 Nihonkai-Chubu Japan Earthquake", Earthquake Spectra, 6, 739-756.

Khintchine, A. Y. (1960), Mathematical Methods in the Theory of Queuing. Griffin, London.

Kircher, C. A., W. T. Holmes and R.V. Whitman (2006), "HAZUS earthquake loss estimation methods", Earthquake Spectra, 22, 297-339.

Klomp, J. and K. Valckx, (2014), "Natural disasters and economic growth: A meta-analysis", Global Environmental Change, 26, 183-195.

Mulargia F., P. B. Stark and R. J. Geller (2017), "Why is Probabilistic Seismic Hazard Analysis (PSHA) still used?", Physics of the Earth and Planetary Interiors, Volume 264, 63-75.

Nogaj, M., P. Yiou, S. Parey, F. Malek, and P. Naveau (2006), "Amplitude and frequency of temperature extremes over the North Atlantic region", Geophysical Research Letters, 33(10).

Nordhaus, W. D. (1991), "To slow or not to slow: the economics of the greenhouse effect", The economic journal, 101(407), 920-937.

Nordhaus, W. D. (2011), "The economics of tail events with an application to climate change," Review of Environmental Economics and Policy, 5.2, 240-257. 
Noy, I. (2009), "The macroeconomic consequences of disasters", Journal of Development Economics, $88,221-231$.

OCDE (2006), "OECD Studies in Risk Management. Japan Earthquakes".

OCDE (2008), "OECD Territorial Reviews. Istanbul, Turkey".

Okuyama, Y. (2003), "Economics of natural disasters: a critical review", Research Paper 200312, Regional Research Institute, West Virginia University, USA.

Omori, F. (1895), "On after-shocks of earthquakes", Journal of the College of Science, Imperial University of Tokyo, 7, 111-200.

Palecki, M.A., S.A. Changnon and K.E. Kunkel (2001), "The nature and impacts of the July 1999 heat wave in the Midwestern United States: learning from the lessons of 1995", Bulletin of the American Meteorological Society 82 (7), 1353-1367.

Pipkin, B. and D. Trent (1997), Geology and the Environment, West/Wadsworth, Belmont.

Posner, R.A. (2006), "Efficient responses to catastrophic risk", Chicago Journal of International Law, 6 (2), 511-525.

Raddatz, C. (2007), "Are external shocks responsible for the instability of output in low income countries?", Journal of Development Economics, 84, 155-187.

Rose, A., J. Benavides, S.E. Chang, P. Szczesniak and D. Lim (1997), "The Regional Economic Impact of an Earthquake: Direct and Indirect Effects of Electricity Lifeline Disruptions", Journal of Regional Science, 37(3), 437-458.

Rose, A. and S. Y. Liao (2005), "Modeling regional economic resilience to disasters: a computable general equilibrium analysis of water service disruptions", Journal of Regional Science, $45(1), 75-112$.

Shibusawa, H. and Y. Miyata (2011), "Evaluating the Dynamic and Spatial Economic Impacts of an Earthquake: A CGE Application to Japan", Regional Science Inquiry, 3(2), 13-25.

Smith, A. (1776), The Wealth of Nations, Book V. London, Methuen \& Co.

Solow R.M. (1956), "A Contribution to the Theory of Economic Growth", The Quarterly Journal of Economics, Vol. 70, No. 1, 65-94.

Stephens, K.U. (2007), "Testimony to the United States Senate, Committee on Homeland Security and Governmental Affairs, Ad Hoc Subcommittee on Disaster Recovery. Postcatastrophe Crisis: Addressing the Dramatic Need and Scant Availability of Mental Health Care in the Gulf Coast." 
Stewart, F. and V. Fitzgerald (2000), War and Underdevelopment: Country Experiences (Vol. 2). Oxford University Press, USA.

Ströbl, E. (2011), "The economic growth impact of hurricanes: evidence from US coastal counties", Review Economics and Statistics, 93 (2), 575-589.

Toya, H. and M. Skidmore (2007), "Economic development and the impacts of natural disasters", Economics Letters, 94(1), 20-25.

West, C. T. and D.G. Lenze (1994), "Modelling the regional impact of natural disaster and recovery: a general framework and an application to hurricane Andrew", International Regional Science Review, 17, 121-150.

Woo G. (1999), The Mathematics of Natural Catastrophes, Imperial College Press, London.

\section{Appendix: The Richter scale and earthquake world fre- quency}

We provide in table 5 the Richter scale, indicating the effects of an earthquake depending on its magnitude as well as its frequency. Table 6 shows the frequency of each type of earthquake at the world scale. 


\begin{tabular}{|c|c|c|}
\hline Magnitude & Average earthquake effects & Average frequency (estimated) \\
\hline$<2.0$ & $\begin{array}{l}\text { Microearthquakes, not felt or felt } \\
\text { rarely. }\end{array}$ & Continual/several million per year \\
\hline $2.0-2.9$ & $\begin{array}{l}\text { Felt slightly by some people. No } \\
\text { damage to buildings. }\end{array}$ & Over one million per year \\
\hline $3.0-3.9$ & $\begin{array}{l}\text { Often felt by people, but very rarely } \\
\text { causes damage. Shaking of indoor } \\
\text { objects can be noticeable. }\end{array}$ & Over 100,000 per year \\
\hline $4.0-4.9$ & $\begin{array}{l}\text { Noticeable shaking of indoor objects } \\
\text { and rattling noises. Felt by most } \\
\text { people in the affected area. Slightly } \\
\text { felt outside. }\end{array}$ & 10,000 to 15,000 per year \\
\hline $5.0-5.9$ & $\begin{array}{l}\text { Can cause damage of varying sever- } \\
\text { ity to poorly constructed buildings. } \\
\text { Felt by everyone. }\end{array}$ & 1,000 to 1,500 per year \\
\hline $6.0-6.9$ & $\begin{array}{l}\text { Damage to a moderate number of } \\
\text { well-built structures in populated } \\
\text { areas. Strong to violent shaking in } \\
\text { epicentral area. }\end{array}$ & 100 to 150 per year \\
\hline $7.0-7.9$ & $\begin{array}{l}\text { Causes damage to most buildings, } \\
\text { some to partially or completely col- } \\
\text { lapse or receive severe damage. Felt } \\
\text { across great distances with major } \\
\text { damage mostly limited to } 250 \mathrm{~km} \\
\text { from epicenter. }\end{array}$ & 10 to 20 per year \\
\hline $8.0-8.9$ & $\begin{array}{l}\text { Major damage to buildings, struc- } \\
\text { tures likely to be destroyed. Damag- } \\
\text { ing in large areas. Felt in extremely } \\
\text { large regions. }\end{array}$ & One per year \\
\hline$\geq 9.0$ & $\begin{array}{l}\text { At or near total destruction - se- } \\
\text { vere damage or collapse to all build- } \\
\text { ings. Heavy damage and shaking ex- } \\
\text { tends to distant locations. Perma- } \\
\text { nent changes in ground topography. }\end{array}$ & One per 10 to 50 years \\
\hline
\end{tabular}

Table 5: Richter Magnitude Scale from United States Geological Survey. 


\begin{tabular}{|c|c|c|c|c|c|c|c|c|c|c|c|c|c|}
\hline$\stackrel{\curvearrowright}{\stackrel{\sim}{\circ}}$ &  & $=$ & $\%$ & 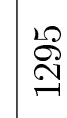 &  & $\frac{N}{N}$ & ิి & & $\vec{\omega}$ & 0 & 0 & $\begin{array}{c}9 \\
\stackrel{9}{+} \\
\stackrel{10}{\longrightarrow} \\
-1\end{array}$ & : \\
\hline$\vec{\sim}$ & -1 & $\stackrel{\theta}{-}$ & $\begin{array}{l}12 \\
0 \\
-10\end{array}$ & $\begin{array}{l}\mathcal{Q} \\
\mathcal{N} \\
\mathcal{N}\end{array}$ & $\begin{array}{l}10 \\
\stackrel{10}{-2} \\
\stackrel{9}{-}\end{array}$ & న. & $\stackrel{\mathfrak{Z}}{\mathrm{c}}$ & & 孚 & $\neg$ & $=$ & 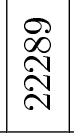 & 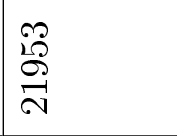 \\
\hline$\stackrel{\circ}{\stackrel{\circ}{\circ}}$ & -1 & $\dddot{\sim}$ & $\stackrel{8}{2}$ & 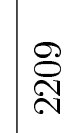 & $\begin{array}{l}f \\
0 \\
0 \\
-1\end{array}$ & $\underset{\sim}{\stackrel{f}{F}}$ & $\grave{\vdots}$ & & ले & 0 & $\vec{\sim}$ & $\begin{array}{l}N \\
N \\
10 \\
\sim \\
\sim\end{array}$ &  \\
\hline  & - & $\stackrel{0}{0}$ & $\exists$ & $\begin{array}{l}\mathscr{8} \\
\infty \\
-\end{array}$ & $\begin{array}{l}12 \\
0 \\
0 \\
0\end{array}$ & : & $\vec{\nabla}$ & & $\stackrel{\leftrightarrow}{\oplus}$ & $\neg$ & $\stackrel{\simeq}{\sim}$ & \begin{tabular}{l}
10 \\
$\infty$ \\
$\infty$ \\
\multirow{+}{\pm}{} \\
-1
\end{tabular} & $\underset{8}{\stackrel{8}{\circ}}$ \\
\hline  & 0 & 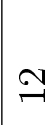 & $\stackrel{\infty}{\infty}$ &  & $\begin{array}{l}\vec{\curvearrowright} \\
\stackrel{\sim}{\sim} \\
-\end{array}$ &  & $\stackrel{c}{c}$ & & $\vec{N}$ & 0 & ָे & $\begin{array}{l}N \\
N \\
\stackrel{N}{n}\end{array}$ & $\begin{array}{l}\vec{F} \\
\stackrel{0}{0} \\
\infty \\
\infty\end{array}$ \\
\hline 용 &  & $\exists$ & $\stackrel{\infty}{\stackrel{\infty}{-}}$ & 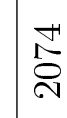 & 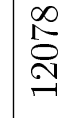 & $\begin{array}{l}\infty \\
\infty \\
\infty \\
\infty\end{array}$ & $\left\{\begin{array}{l}0 \\
0 \\
0\end{array}\right.$ & & $\stackrel{\mathcal{F}}{\mathscr{F}}$ & $\sim$ & $\begin{array}{l}\hat{0} \\
\infty \\
-1\end{array}$ & $\begin{array}{l}10 \\
\infty \\
0 \\
\mathscr{D} \\
\stackrel{2}{2}\end{array}$ & $\stackrel{\sim}{\stackrel{N}{F}}$ \\
\hline 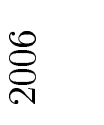 & $\curvearrowright$ & 0 & I & $\stackrel{\overbrace{}}{\stackrel{N}{二}}$ & 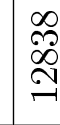 & \&. & $\hat{\mathfrak{g}}$ & & $\stackrel{\infty}{\rightarrow}$ & $\sim$ & \begin{tabular}{l}
$\infty$ \\
\multirow{\infty}{\infty}{}
\end{tabular} & $\begin{array}{l}\infty \\
0 \\
\mathscr{0} \\
\mathscr{\rho} \\
\mathscr{\rho}\end{array}$ & $\begin{array}{l}12 \\
0 \\
0\end{array}$ \\
\hline$\stackrel{20}{\stackrel{2}{0}}$ & - & 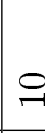 & $\stackrel{9}{\rightarrow}$ & $\begin{array}{l}\Re \\
\mathscr{6} \\
-1\end{array}$ & $\begin{array}{l}\curvearrowright \\
\stackrel{\sim}{\sigma} \\
\stackrel{-}{\sim}\end{array}$ & $\frac{\sigma}{\sigma}$ & 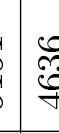 & & 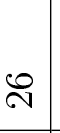 & 0 & $\vec{\infty}$ & \begin{tabular}{l}
$\infty$ \\
$\stackrel{\infty}{+}$ \\
\multirow{6}{*}{} \\
$\infty$
\end{tabular} & 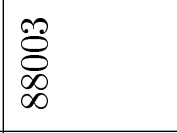 \\
\hline$\underset{\sim}{\stackrel{\leftrightarrow}{\circ}}$ & $\sim$ & $\exists$ & $\exists$ & $\begin{array}{l}10 \\
10 \\
-10\end{array}$ & $\begin{array}{l}\infty \\
\infty \\
\infty \\
0 \\
-\end{array}$ & 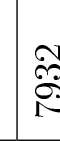 & 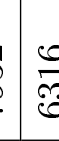 & & 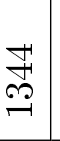 & $\stackrel{\wp}{\ominus}$ & 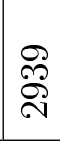 & $\underset{\vec{\sigma}}{\vec{\sigma}}$ & 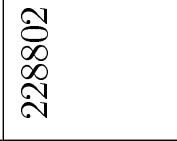 \\
\hline  & - & 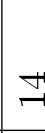 & f & 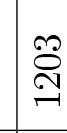 & $\underset{\infty}{\mathscr{\infty}}$ &  & $\hat{\imath}$ & & $\begin{array}{l}0 \\
\stackrel{2}{2} \\
\stackrel{2}{N} \\
\end{array}$ & $\stackrel{\vec{m}}{\rightarrow}$ & \begin{tabular}{|l}
$\infty$ \\
0 \\
0 \\
-0
\end{tabular} & $\underset{\sigma}{\stackrel{\sigma}{\vec{\sigma}}}$ & 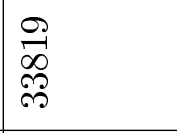 \\
\hline$\underset{ᄋ}{\stackrel{ᄋ}{ి}}$ & 0 & $\stackrel{9}{\circ}$ & $\stackrel{\sim}{\stackrel{\sim}{\sim}}$ &  & 芳 & $\underbrace{\infty}_{1}$ & $\frac{\sigma}{\sigma}$ & & $\begin{array}{l}\stackrel{\sim}{\oplus} \\
\stackrel{=}{=}\end{array}$ & $\stackrel{\circ}{=}$ & $\begin{array}{l}\infty \\
\stackrel{\infty}{\Omega} \\
\stackrel{\sim}{\sim}\end{array}$ & $\underset{N}{\stackrel{N}{ \pm}}$ & $\begin{array}{l}10 \\
0 \\
0 \\
-1\end{array}$ \\
\hline$\underset{\sim}{\stackrel{\circ}{\circ}}$ & - & 10 & $\stackrel{\check{\sim}}{\sim}$ & $\underset{\sim}{\stackrel{N}{\sim}}$ & 穴 & $\begin{array}{l}\mathscr{0} \\
\mathscr{0} \\
\mathscr{0}\end{array}$ & $\frac{\vec{v}}{7}$ & & $\vec{J}$ & $\neg$ & 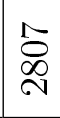 &  & $\begin{array}{l}\hat{N} \\
20 \\
\stackrel{2}{N} \\
\text { N }\end{array}$ \\
\hline$\underset{\overbrace{}}{\stackrel{ి}{\circ}}$ & - & $\exists$ & $\stackrel{0}{J}$ & $\underset{\sim}{\stackrel{H}{*}}$ & $\stackrel{\infty}{\infty}$ & $\begin{array}{l}\hat{N} \\
\alpha \\
\sigma\end{array}$ & $\begin{array}{l}15 \\
0 \\
0\end{array}$ & & $\begin{array}{l}\mathscr{D} \\
\stackrel{\mathcal{O}}{ }\end{array}$ & 10 & $\frac{尺}{\stackrel{\overbrace{}}{\infty}}$ &  & $\vec{\Re}$ \\
\hline 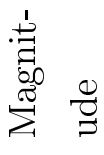 & $\begin{array}{c}0 \\
0 \\
0 \\
0 \\
\infty\end{array}$ & $\mid \begin{array}{l}0 \\
0 \\
1 \\
1 \\
1 \\
1\end{array}$ & $\begin{array}{l}9 \\
0 \\
1 \\
0 \\
0\end{array}$ & $\begin{array}{c}0 \\
10 \\
0 \\
0 \\
10\end{array}$ & 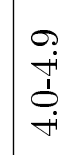 &  & a & & $\begin{array}{l}\sigma \\
\dot{T} \\
\underline{d} \\
\dot{-}\end{array}$ & $\begin{array}{l}\stackrel{9}{0} \\
\dot{1} \\
\stackrel{1}{0}\end{array}$ & 0 & $\begin{array}{c}\vec{\pi} \\
\stackrel{T}{0} \\
\oplus\end{array}$ &  \\
\hline
\end{tabular}

